I thank Dr. J. J. A. Reid, who at the time of this study was County Medical Officer of Health, Buckinghamshire; Dr. A. W. Pringle, Aylesbury Area Medical Officer and Divisional School Medical Officer; the Buckinghamshire Education Department and the head teachers of the schools involved for their co-operation and help in this survey; Mrs. B. Hunt for the analysis of the data; Professor D. D. Reid who gave helpful advice in the preparation of this paper; and the field workers who included Mrs. B. Hunt, Miss S. J. Newby, S.R.N., Mrs. M. Pant, S.R.N., Miss J. P. E. Stocks, S.R.N., and Miss J. V. Tudhope, S.R.N.

\section{References}

Classification of Occupations (1970). (1972). Office of Population Censuses and Surveys, London, H.M.S.O.

Colley, J. R. T. (1970). Proceedings of the Third International Symposium on Bronchitis, ed. N. G. M. Orie and R. van der Lende, p. 8. Assen, Netherlands, Royal Van Gorcum.

Colley, J. R. T., and Reid, D. D. (1970). British Medical fournal, 2, 213.

Colley, J. R. T., and Reid, D. D. (1970). British Medical fournal, 2, 213. Memorial Fund Quarterly, 47, 215.

Krueger, D. E., Rogot, E., Blackwelder, W. C., and Reid, D. D. (1970). fournal of Chronic Diseases, 23, 411.

Norman-Taylor, W., and Dickinson, V. A. (1972). Community Medicine,

Todd, G. F. (1972). Statistics of Smoking in the U.K., 6th edn., London Tobacco Research Council.

\title{
Choreo-athetosis and Encephalopathy Induced by Phenytoin
}

\author{
D. L. MCLELLAN, M. SWASH
}

\section{Summary}

Two patients with intractable epilepsy who had been treated with various combinations of anticonvulsant drugs developed phenytoin encephalopathy. In both patients choreo-athetoid involuntary movements were prominent. Blood phenytoin concentrations were above $30 \mu \mathrm{g} / \mathrm{ml}$. When phenytoin was given in smaller doses and its level in the blood fell the involuntary movements and other clinical manifestations disappeared.

\section{Introduction}

Nystagmus, ataxia, dizziness, and drowsiness are well-known features of phenytoin toxicity which usually occur when the blood level is greater than $20 \mu \mathrm{g} / \mathrm{ml}$ (Buchthal et al., 1960). There have been few reports of other toxic effects on the central nervous system though Glaser (1973) pointed out that a reversible encephalopathy may occur in some patients treated with large doses of the drug. We describe two patients in whom choreo-athetoid involuntary movements were a prominent and presenting feature and in whom the involuntary movements and the encephalopathy were closely correlated with very high blood phenytoin concentrations.

\section{Case Reports}

CASE 1

A 31-year-old man who had attended hospital for many years for management of epilepsy was admitted for investigation of involuntary movements and intractable seizures. He had had a febrile convulsion when 2 years old and had had recurrent petit mal and major generalized seizures since he was 7. An electroencephalogram when he was aged 13 showed typical, generalized, three-per-second spike-and-wave complexes and diffuse bursts of theta and delta activity. When assessed for industrial training when aged 21 he had an I.Q. of 84 on the Wechsler Intelligence Scale. He was treated with various combinations of anticonvulsants,

\footnotetext{
Department of Neurology, Section of Neurological Sciences, London Hospital, London E1 1BB

D. L. MCLELLAN, M.B., M.R.C.P., Senior Registrar

M. SWASH, M.D., M.R.C.P., Consultant Neurologist
}

including troxidone, ethosuximide, primidone, and phenytoin, but he continued to have two or three major seizures a month. When he was aged 29 Hodgkin's disease was diagnosed by biopsy of an enlarged cervical lymph node. No involvement of liver, spleen, or para-aortic nodes was seen on laparotomy and he was treated with radiotherapy to the neck. There had been no recurrence. Treatment with phenytoin $300 \mathrm{mg}$, phenobarbitone $150 \mathrm{mg}$, and ethosuximide $750 \mathrm{mg}$ daily was continued. Two years later the seizures became more frequent (two to four a week) and primidone $750 \mathrm{mg}$, carbamazepine $800 \mathrm{mg}$, and phenytoin $450 \mathrm{mg}$ daily were gradually substituted for the previous treatment. During the next six weeks he complained of blurred vision and ataxia, leading to frequent falls. He continued to take the drugs. The seizures continued unchanged.

On admission to hospital he was slightly drowsy but orientated. Several minor seizures were observed. He had grade I nystagmus in all directions and upward conjugate gaze was impaired. There was generalized chorea which was present at rest and was enhanced by movement, particularly by walking. Slurred and hesitant speech seemed to be due to interposed choreic movements of the lips and tongue. In the outstretched upper limbs choreiform involuntary movements were accompanied by irregular postural lapses of the fingers, which were thought to be typical of asterixis rather than chorea. The gait was unsteady, but there were no cerebellar signs in the limbs. There was no weakness or sensory impairment, the tendon reflexes were brisk, and both plantar responses were flexor. Hyperplasia of the gums was noted. The increased frequency of seizures and the encephalopathy with involuntary movements were first ascribed to a degenerative or infective disorder associated with the Hodgkin's disease. The haemoglobin, white cell count, E.S.R., liver function tests, blood urea and electrolytes, skull and chest $x$-ray examinations, and brain scan were normal. The background activity in the E.E.G. was fragmented and slowed and there was an excess of diffuse, irregular delta activity of moderate voltage. Generalized atypical spike-and-wave activity was prominent. The blood phenytoin concentration was $37 \mu \mathrm{g} / \mathrm{ml}$.

The possibility of phenytoin encephalopathy was considered. The daily dose of phenytoin was reduced to $200 \mathrm{mg}$ daily and that of primidone increased to $1 \mathrm{~g}$. Carbamazepine $800 \mathrm{mg}$ daily was continued. During the next six days the patient became more alert, the chorea, ataxia, and nystagmus disappeared, and the blood phenytoin level fell to $16 \mu \mathrm{g} / \mathrm{ml}$. The seizures at first increased in frequency but then abated. Three weeks later he returned to work. Neurological findings at that time were normal.

\section{CASE 2}

This 15-year-old boy was referred for management of uncontrolled epilepsy. He had had frequent minor and major seizures since the age of 2 when he had presented in status epilepticus. He had been treated with varying combinations of phenytoin, phenobarbitone, ethosuximide, and sulthiame and had been almost free 
of seizures for several periods of a few months. Nevertheless, seizures usually oocurred several times each week and there had been several episodes of prolonged serial or status epilepticus. When aged 13 he was taking phenytoin $200 \mathrm{mg}$ and phenobarbitone $90 \mathrm{mg}$ daily in divided doses. His school progress was poor. His full-scale I.Q. was 83 (verbal 75, performance 87) (Wechsler Intelligence Scale). The E.E.G. showed a poorly organized, irregular background activity with frequent bursts of generalized theta and delta activity, atypical spike-and-wave complexes, and scattered sharp waves and spikes. The daily dose of phenytoin was increased to $300 \mathrm{mg}$ but there was little improvement. When aged 15 he was taking phenobarbitone $180 \mathrm{mg}$ sulthiame $600 \mathrm{mg}$, and phenytoin $300 \mathrm{mg}$ daily. His epilepsy remained uncontrolled and the phenytoin dose was increased to $400 \mathrm{mg}$ daily. Seizures continued several times daily and ataxia, dysarthria, nystagmus, diplopia, and drowsiness developed. This was recognized as a toxic effect of anticonvulsant therapy: sulthiame was withdrawn and phenytoin reduced to $300 \mathrm{mg}$ daily. Two weeks later there was a very slight residual ataxia with nystagmus on lateral gaze. The seizures continued several times daily. The dose of phenobarbitone was reduced to $120 \mathrm{mg}$ daily, primidone $375 \mathrm{mg}$ daily was added, and phenytoin $300 \mathrm{mg}$ daily was continued. During the next two weeks the patient became very drowsy and confused, developed dysarthria and nystagmus, and became unable to walk without help. The seizures, both major and minor, became more frequent.

On admission to hospital all anticonvulsant therapy was stopped. The next day he was more alert but remained confused. There was a coarse, grade I lateral nystagmus. His gait was unsteady and he tended to take irregular, long, loping strides. Choreo-athetoid movements were seen in all four limbs and in the trunk. These were accentuated by voluntary movement and seemed to account, in part, for his peculiar gait. There was pronounced dystonic rigidity in all four limbs with unsustained knee and ankle clonus. The plantar responses were flexor. The nystagmus disappeared two days after the anticonvulsant therapy was stopped but the involuntary movements persisted and major seizures continued to occur two to four times daily. An E.E.G. showed pronounced generalized slowing and irregularity of background activity with some paroxysmal theta and delta activity and scattered sharp forms. Skull and chest $x$-ray films and a brain scan were normal. The cerebrospinal fluid contained protein $10 \mathrm{mg} / 100 \mathrm{ml}$ and leucocytes $2 / \mathrm{mm}^{3}$. An air encephalogram showed moderate dilatation of the lateral ventricles and of the right temporal horn. The subarachnoid spaces were normal. The full-scale I.Q. (Weschler Intelligence Scale) was 65 (verbal 68, performance 67). The blood phenytoin was $50 \mu \mathrm{g} / \mathrm{ml}$ and the blood phenobarbitone 1.4 $\mathrm{mg} / 100 \mathrm{ml}$. The plasma calcium was normal.

Anticonvulsant treatment was started again on the third day with phenobarbitone $180 \mathrm{mg}$ and phenytoin $150 \mathrm{mg}$ daily. Folic acid was also given. He continued to have frequent nocturnal convulsions but the athetosis gradually disappeared during the next seven to 10 days. Four weeks after admission the blood phenytoin was $5 \mu \mathrm{g} / \mathrm{ml}$ and the blood phenobarbitone $1 \mathrm{mg} / 100$ $\mathrm{ml}$. Apart from slight clumsiness and mental retardation there was no neurological abnormality.

\section{Discussion}

The term "phenytoin encephalopathy" was applied by Glaser (1973) to the rare syndrome of increasing intellectual impairment, increased frequency of seizures (Levy and Fenichel, 1965), and focal neurological signs induced by phenytoin and reversed when the drug is stopped. The focal signs may include hemiparesis, hemisensory disturbance, and dysphasia. In both our patients, however, the most striking feature was the development of choreo-athetoid involuntary movements and dystonia. The involuntary movements were associated with very high blood levels of phenytoin, but not of phenobarbitone, and disappeared when blood phenytoin levels were lowered. Previous reports of dose-related toxic effects of phentyoin have emphasized the appearance of nystagmus and cerebellar ataxia (Merritt and Putnam, 1939; Roseman, 1961), and Buchthal et al. (1960) related these signs to blood phenytoin levels greater than 20 $\mu \mathrm{g} / \mathrm{ml}$. Involuntary movements and encephalopathy were not seen in these large series of patients.

Previous descriptions of phenytoin encephalopathy are few. Of the eight patients described by others (Morris et al.,1956; Levy and Fenichel, 1965; Logan and Freeman, 1969) only one had involuntary movements. Blood phenytoin levels were not estimated in any of these cases. One of the two patients described by Logan and Freeman (1969) developed severe chorea, athetosis, and dystonia affecting the face and limbs when phenobarbitone $240 \mathrm{mg}$ daily was added to phenytoin $400 \mathrm{mg}$ daily. These signs disappeared, as in our patients, when phenytoin was reduced to $200 \mathrm{mg}$ daily, despite an increase in the dose of phenobarbitone to $360 \mathrm{mg}$ daily. The patient, however, was mentally retarded and had previously been noted to have mild choreo-athetosis. Williamson (1940) suggested that patients with brain damage and mental retardation might be particularly susceptible to phenytoin but at that time blood phenytoin estimations were not available. In both our patients the involuntary movements and encephalopathy were clearly related to the high blood phentyoin levels and only in the second was there evidence of significant pre-existent brain damage.

As would be expected of a toxic effect found in relation to the treatment of severe epilepsy most cases of phenytoin encephalopathy have been in patients treated with combinations of anticonvulsants. This was so in both our patients. Indeed, in one (case 2) chorea did not appear until primidone was added. Primidone and phenobarbitone are unlikely to have caused increased blood phenytoin levels (Kutt, 1973), but sulthiame may have done so (Hansen et al., 1968). The pathogenesis of involuntary movements or of seizures and focal neurological signs with very high blood phenytoin concentrations is obscure. Phenytoin has been shown both clinically (Buchthal et al., 1960; Roseman, 1961) and experimentally (Kokenge et al., 1965) to be toxic to the cerebellum and degeneration of Purkinje cells has been seen after single large overdoses in man (Kokenge et al., 1965). In our patients, however, cerebellar signs apart from nystagmus were not prominent. Possibly they were masked by the involuntary movements, since both patients were unsteady in their gait.

Involuntary movements have not been described in patients taking phenytoin alone. Possibly, therefore, the syndrome we have described is due in some way to an interaction occurring at a neuronal level between phentyoin in high concentration and other anticonvulsant drugs rather than solely an effect of the high phenytoin concentration itself.

Logan and Freeman (1969) referred to their two patients as presenting with a "pseudo-degenerative" disease of the nervous system and the same problem of diagnosis arose in our patients. Since phenytoin encephalopathy is a reversible disorder estimation of the blood phenytoin concentration is a particularly valuable diagnostic test.

\section{References}

Buchthal, F., Svensmark, O., and Schiller, P. J. (1960). Archives of Neurology (Chicago), 2, 624.

Glaser, G. H. (1973) In Antiepileptic Drugs, ed. D. M. Woodbury, J. K. Penry, and R. P. Schmidt. Pp. 219-226. New York, Raven Press. Hansen, J. M., Kristensen, M., and Skovsted, L. (1968). Epilepsia, 9, 17. $15,823$.

Kutt, H. (1973). In Antiepileptic Drugs, ed. D. M. Woodbury, J. K. Penry, and R. P. Schmidt, pp. 169-180. New York, Raven Press.

Levy, L. L., and Fenichel, G. M. (1965). Neurology (Minneapolis), $15,716$.

Logan, W. J., and Freeman, J. M. (1969). Archives of Neurology (Chicago), 21,631 . Merritt, H. H., and Putnam, T. J. (1939). Archives of Neurology and Psy-
chiatry (Chicago), 42, 1053.

Morris, J. V., Fischer, E., and Bergin, J. T. (1956). British Medical fournal, $2,1529$.

Roseman, E. (1961). Neurology (Minneapolis), 11, 912.

Williamson, B. A. M. (1940). Fournal of Mental Science, 86, 981. 